\title{
Project Based Learning in Engineering Schools: The Roles of Supply Management, Procurement, Designers and Builders of a New Product
}

\author{
Muhammed S. Maddi \\ School of Mechanical \& Manufacturing Engineering, Dublin City University, D. 9, Ireland \& \\ College of Economics Azzytuna University,Bani Walid Libya \\ Rubén Lostado Lorza \\ Department of Mechanical Engineering, University of La Rioja, Spain
}

Saifallah Benjread

College of Business, School of Accounting and Finance. Dublin Institute of Technology, Dublin 2, Ireland \& Economy College, Aziza County. Tripoli University Libya

\author{
John Geragthy \\ Enterprise Process Research Centre, School of Mechanical \& Manufacturing \\ Engineering, Dublin City University, Dublin 9, Ireland \\ Paul Davis \\ DCU Business School, Dublin City University, Glasnevin Dublin 9, Ireland
}

\begin{abstract}
The Design, Development and Supply Management of a new product are hard and complicated tasks which require knowledge in several disciplines such as Engineering, Research and Development, Marketing and Human Resources. Acquiring these tasks by engineering students represents a major advancement in preparation for real life as future engineers. All of these tasks are hardly taught jointly through traditional learning methods, so engineering students poorly assimilate them. New learning techniques such as project-based learning, facilitates the assimilation of all these tasks giving students a much more comprehensive and realistic set of competences for their future professional life. In this paper, we present a case study of project-based learning, involving the Design, Development and the role of the Marketing and Supply Chain Management of a new product within a classroom environment. The project set for the students relates to the manufacturing of a new motorcycle. It was carried out by students of engineering schools in Spain as part of a National Competition. Engineering schools are involved in the project competition in a real race held on a professional circuit.
\end{abstract}

\section{Introduction}

Despite of the number of Spanish students who have dropped out in 2012 decreasing, the school dropout rate remains the highest in the EU. In the European Union, the number of young people who have dropped out has declined to $14 \%$ in 2012, while in Spain, the dropout rate is currently 30\% [29]. At the 3rd Level within Universities, these numbers have increased to between 40 and $50 \%$, and in the case of engineering schools they are at $90 \%$ [20]. Moreover, 25\% of Spanish teachers lose at least $70 \%$ of instructional time due to disruptive behaviours of students compared to $30 \%$ of the European average [31].

The fundamental causes for such disruption to instructional time and early exit from educations are mainly due to the motivations of young people, which is attributable to [35]:

1. Socio-cultural and family factors

2. Personal variables of the student

3. What the teacher teaches and how the teacher teaches?

Based on these three main causes of demotivation, teachers can act only on the third one, changing the method of teaching. It is known that the Project Based Learning (PBL) is a learning method capable of increasing student motivation, increased 
school attendance and improved class participation [20].

PBL is a learning model in which students plan, evaluate and carry out projects that have real-world implications and activities [9]. In it (Project Based Learning) several interdisciplinary learning activities are developed at the concurrently, which ensures students acquire knowledge in a variety of disciplines [23]. Project learning is difficult and requires dedication and hard work by all those involved (both teachers and students). Basically, using the Project Based Learning, students develop skills such as:

- The ability to solve problems and develop complex tasks [23].

- The ability to work in teams which vital for organizational growth [31].

- Development of higher order thinking skills (information search, analysis, and synthesis, and conceptualization, critical use of information, systems thinking, critical thinking, research and metacognition) [31].

- Increased knowledge and skill in the use of Information and computer technology ICT in a project [23].

- Promotion and acceptance of responsibility for individual learning [32].

However, this learning method has some disadvantages, which if not detected early, can a negative impact on the learning experiences of the student:

- There is a lower coverage in some subjects in exchange for a greater depth in other subjects.

- It requires a very good organization by the teachers and by the students.

- In the design of the approach, the organization should involve the teacher and other experts such that the teacher and the technicians should have basic knowledge of the project design.

- It can be difficult to integrate and match different themes to communicate between participant teams.

- Time and patience are required to remain open to different ideas and opinions.

- Difficulty to act with poorly motivated students or with negative experiences in their academic performance.
- Difficulty in applying the methodology to students who lack knowledge related to the contents on which you want to apply the PBL.

The work presented in this paper shows a case study of Project-Based Learning applied to Design, Development and Supply Management of a racing motorcycle. This project (MotoStudent) is a university competition in which 17 teams with over 200 students taken from industrial engineering schools in Spain, compete for the best Project in the Design, Development and Supply Management of a motorcycle.

The teams participating in the competition have to work in the design, development and construction of a prototype of Moto3 with $250 \mathrm{cc}$ engine and four strokes, from a basic kit provided by Moto Engineering Foundation (MEF). MEF is a non-profit organization that aims to foster contacts and training and innovation between industry and educational bodies. One of the purposes of this competition is to integrate university teams into a motorcycle manufacturing company, so as to develop and manufacture a prototype under some technical and economic constraints.

This competition is a challenging task especially for students, due to time constraints. This is because within three semesters students are expected to demonstrate and test their ability of innovation. They are asked to create and apply their skills as future engineers and compete with teams from other universities.

This paper shows the importance of the management role in producing a new product in particular how the roles of the Marketing and Supply Chain management relate to manufacturing [32].

\section{Project Organization}

The organizational structure of a real project often restricts the availability of resources to carry out the project. The classic functional organization is a hierarchy where each employee has a clear and distinct structure through which they report. Project members are grouped by specialty. These may include: a production department, a marketing department, an engineering department and an accounting department [26].

Also in each of these departments, such as the engineering department, a subdivision of smaller functional units of the organizations may exist, such as a mechanical section and an electrical section. Traditionally, the engineering department of a functional organization undertakes a project independent of some of the departments such as the production or marketing departments.

In this case, the collaboration and participation of students from all relevant disciplines and 
departments are required in order to foster and create an environment for a project-oriented organization in which most of the organization's resources are shared for the purposed of the project [33].

\section{The Role of Assignments}

This section shows the relevant roles, allocation of roles and responsibility attached to such roles. It describes the roles of Project manager, procurement and supply chain in the project, followed by the roles designers and builders and lastly it presents the roles of experimental technicians.

There is a positive relationship between people who work with various backgrounds in research and development of new products and high quality and performance. This kind of work approach is called a cross- functional group; it enhances the organization's performance through advanced communication to generate an external network of information in the business environment [14]. This can be referred to as the key role of core capabilities in a new product process and development project because traditionally core capabilities constitute clusters of technical system, skills, and innovation within an organization. However, there is down side of core capabilities that can often restrain innovation.

A project manager therefore has to tackle this paradox of competences to take advantage of the positive side and avoid being hampered by rigidities of capabilities in order to improve the performance of an organization [17]. What are the key drivers to develop a new product? Results of several of New Products studies show hundreds of new product failures and successes of business. Therefore, managers need to discover the key components of new product performance, where "performance" is determined in different ways, such as profitability, market share, achieving objectives, impact on the company and speed to market. Some studies claim that there are various key components that have a significant impact on a new products success. These factors include product advantage, meeting costumer's needs, market potential, predevelopment task proficiencies, and committed resources [11].

In order to avoid losing learning experiences, firms ought to apply numerous strategies to distribute knowledge across projects. For examples, an organization can use a well-established product development process, professional full-time project managers as well as modularization of the product [20]. Therefore, managers of new product development can accomplish their aims through a usage of specific techniques and tools. This would provide a better opportunity for success rather than investment in high levels of technology, and it can have a significant impact on firms' investment plans for the future business [21].

\subsection{Roles of the Project Manager}

The project manager is the person who has overall responsibility for the planning and execution of any project. He/she must possess a combination of skills including strong leadership skills as well as interpersonal skills, time management skills and conflicts resolution skills. One of the important tasks of the project manager is to recognize the risks that directly affect the likelihood of success or failure of the project, as well as the measurement of risks throughout the project life cycle. A good project manager can reduce risk significantly by a policy of open communication and making sure each project participant has an opportunity to express their views and concerns. $\mathrm{He}$ or she is responsible for controlling/managing risk in order to avoid failure as well as minimizing the effect of uncertainty in the course of a project.

In this case study, the role of project manager for MotoStudent was assigned to a student chosen by the faculty. This student was expected to meet the requirements listed above; in addition to that he or she was expected to have personal and professional skills in order to address a series of concerns. To avoid organizational problems in carrying out of this project, weekly monitoring meetings were convened in which team members met with teachers to address issues of concerns. The Figure 1 below shows the common project management roles in organization.

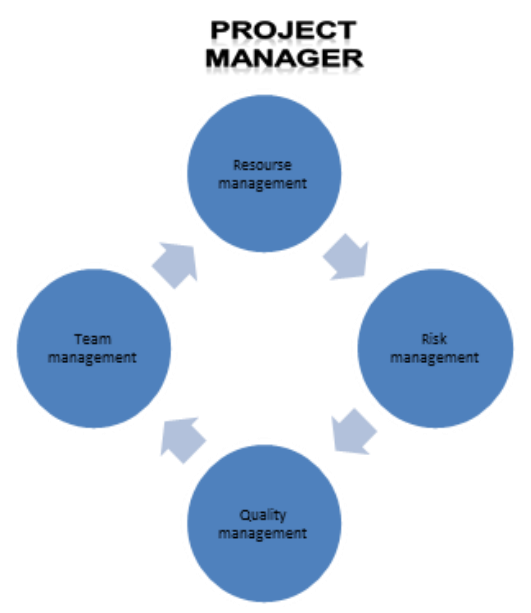

Figure 1. Project Manager Duty

Successful project management requires starting with a good plan and strategy for the project followed by a continuous focus on resource management, risk management, quality management and team management. 


\subsection{Roles of Procurement and Supply Chain management}

The US Council of Supply Chain Management Professionals (CSCMP) defined "Supply chain management encompasses the planning and management of all activities involved in sourcing and procurement, conversion, and all logistics management activities" [23]. Many studies have used the phrase supply chain management as a synonym or alternative to logistics. However, given that various business operations are integrated in supply chains the phrase and meaning goes further and is not synonymous to logistics. This notion can be obvious in new product development because logistics would not control the new product development process or customers as the supply chain does [6].

In this case, since the time and resources which were available to students for successful completion of the project was limited, two students spent most of the duration of the project in procurement. In addition, these students had to obtain the funding from the sponsors for manufacturing/procuring the other components because the organization does not provide for instance the chassis, rear suspension and fuel tank.

According to [35] supply chain management is defined as the sequence of events in a goods flow, which adds value to the value of a specific good. In a very basic explanation the supply chain is linking the supplier with the consumer through a dedicated service. As shown below in the figure the successful SC Manager should have the following skills:

A. Creation of detailed project work plans and strategy for identifying scope, projects assigned, key milestones and deliverables, and updating as appropriate to meet changing needs.

B. Managing directly day-to-day all operational aspects.

C. Classifying resources needed and assigning individual responsibilities.

D. Managing meetings with project team regularly.

E. Co-ordination of cross-functional teams.

This implies that the key to success key of SCM is innovation, customization, scalability (integration of unlimited number of clients, multichannel, security, and flexibility [33]. It is only in recent years, with the development of focused undergraduate courses in logistics and SCM that people are coming into the logistics/SCM function directly from Institutions of higher education (Figure 2 ). The annual survey of logistics managers and directors in the US carried out by the SCM Research Group at the Ohio State University gives an insight into the characteristics of the typical supply chain manager. For example the results of the 2002 study shows that of managers, $39 \%$ of the survey respondents, $89 \%$ had a bachelors degree, $63 \%$ had a masters degree and $18 \%$ had professional qualifications [33].

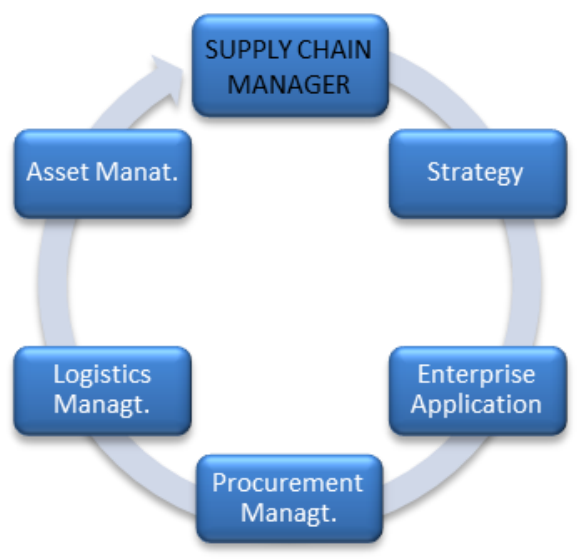

Figure 2. Supply chain Manager Duty

Many countries now provide a range of development activities for supply chain managers. Many of these activities take place around the professional bodies, examples of which include the Council of SCM Professionals (www.cscmp.org) and the Chartered Institute of Logistics and Transport in the UK (www.ciltuk.org.uk). The achievement of supply chain excellence in the marketplace can only be built upon excellence in the skills and competencies of the people who manage those supply chains [19].

In addition, the use of an electronic procurement (e-Procurement) strategy which is a type of buying and selling between producers and consumers, through the use of information technology (IT) and communications is significant. This strategy allows both sides to establish a base of qualified and registered users, which is useful when searching for buyers or sellers and to select the bidding price or new tender [18]. This linkage has become important in new product development as it enables faster communication and closer linkages between parties in the supply chain. 


\subsection{Roles of Designers and Builders}

The roles of designers and builders are truly important because these roles and relationships directly impact how effective the actual execution of the project will be. In this case, a team of ten students that are well coordinated were assigned with responsibilities for the design and manufacture of different components forming the motorcycle. The design of these components was based on advanced techniques of Computer Aided Engineering (CAE) based on Finite Element Method (FEM), which helped to optimize the weights and the resistance of mechanical components. Figure 3 shows the motorcycle designed by students with CATIA design software in the subject CAD / CAE.

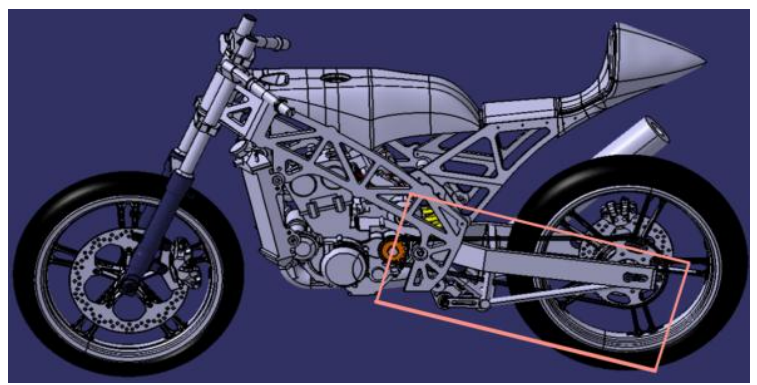

Figure 3. 3D modeling of the Whole Motorcycle Designed with Catia

Also, all components were produced by students in the machining centers and workshops in the universities, so that students conducted the manufacturing via Computer Aided Manufacturing (CAM). On the left side of Figure 4 the results of the FEM model of the motorcycle rear swing arm are depicted and the manufactured rear swing arm is depicted on the right.

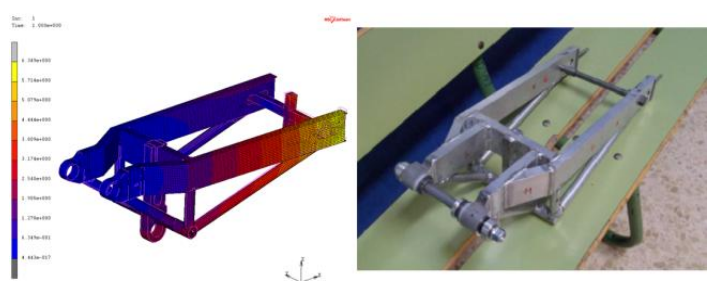

Figure 4. Design and Manufacturing of the Rear Swing

\subsection{Roles of Experimental Technician}

Another important role in carrying out the project is the role of the experimental technicians. Once the motorcycle prototype was developed, a group of three students with the assistance of a 'test pilot' conducted an experimental trial of the prototype on a test track. The objective of this trial was for verification and validation of the operations of the motorcycle. Figure 5 shows the experimental technical (student) testing the prototype of motorcycle built. The experimental test was always supervised by teachers and technical specialists of the organization in order to validate the quality of the motorcycle built according to the rules of the competition.

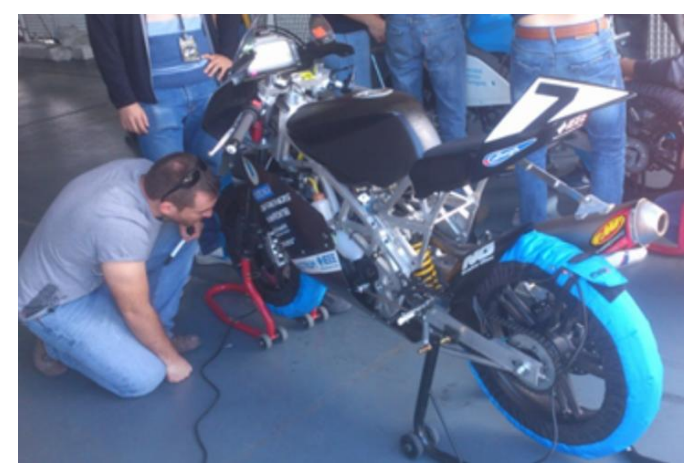

Figure 4. Experimental Technicians Working on the Motorcycle prototype built

\subsection{Roles of Marketing and Human Resource}

Marketing and human resource management are important key actors in the development of new product innovation. Competition nowadays is no longer as it was before which was between large and small companies rather it is now between fast and slow growth companies. Hence, it is very important for firms to reduce the cycle time of product development processes. They do this by employing new methods, such as new development teams, which concentrate on human and rapid prototyping technologies [29].

According to the American Marketing association, marketing is 'the process of planning and executing the conception, pricing, promotion, and distribution of ideas, goods and services to create exchanges that satisfy individual and organizational goal's [29]. That means the marketing objective is realized in the output of customer satisfaction and the creating of exchanges.

Research previously carried out [8] presented an empirical study showing that there is a valid and distinct demarcation between internal marketing (IM) and human resource managers (HRE), that IM is an important antecedent to HRE. They set out that Human resource management, by name and concept was largely a product of US writings in the early 1980s where its link to organizational effectiveness was clearly identified and used as a justification for its adoption within firms. Early organizational behaviour writings were significant at the time in that they began to recognize the potential contribution of human resources to meet strategic 
objectives. They concluded that the interface between marketing and HRM reflects the importance of co-ordinating functional strategies, thereby facilitating effective overall corporate strategy implementation.

Figure 5 below shows the importance of four priorities that need to be considered by any successful marketing manager, the first is customer needs as many empirical studies have mentioned, the others include Preliminary Concept \& Definition, Production Line \& Quality testing and also delivery and customer support.

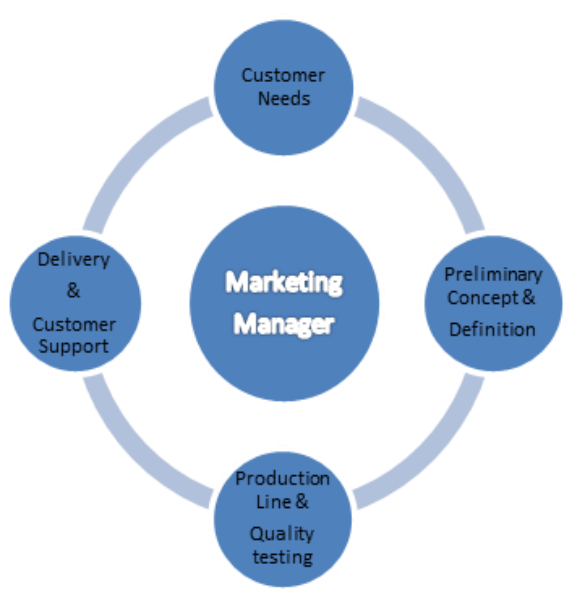

Figure 5. Marketing Manager Priorities

Furthermore, increasing the process by which new products are launched to the marketplace has become a strategic action crucial in many markets. An emerging qualification for new-product development success is the integration of information technology with innovative management practice; technology can play a major role in creating information dissemination, process progress, reductions in time and costs, and enhanced project management [12].

However, there are different reasons that may delay the new product development, including poor description of product requirements, technical uncertainties, superior management support, dearth of resources, and weak project management. Other areas include the lack of additional support for the management and organisational approach, lack of attention to details of business, a slim support for innovation, lack of strategic thoughts, and poor industrialized capacities [24]. Also, the over control of top management on a new product development project affects the knowledge creation in many ways, both hindering and facilitating knowledge creation. Principally, this control centers on explicit knowledge, and not implicit one, which could limit the general ability for knowledge creativity and eventually innovation [27].

In this case, a market study was conducted by the students with the goal of the establishing the future sale potential of this prototype motorcycle. The existing demand and interest to acquire this type of motorcycle was studied by the students themselves.

Furthermore, existing competitors and the strengths, weaknesses and total cost of mass production of the prototype were studied.

In 2008 [22] research showed the strong relationship between supply chain management, logistic and marketing in production and services organizations. Figure 6 below highlighted the connection between the three of them, which is considered as the domain of this broader interpretation of operations management.

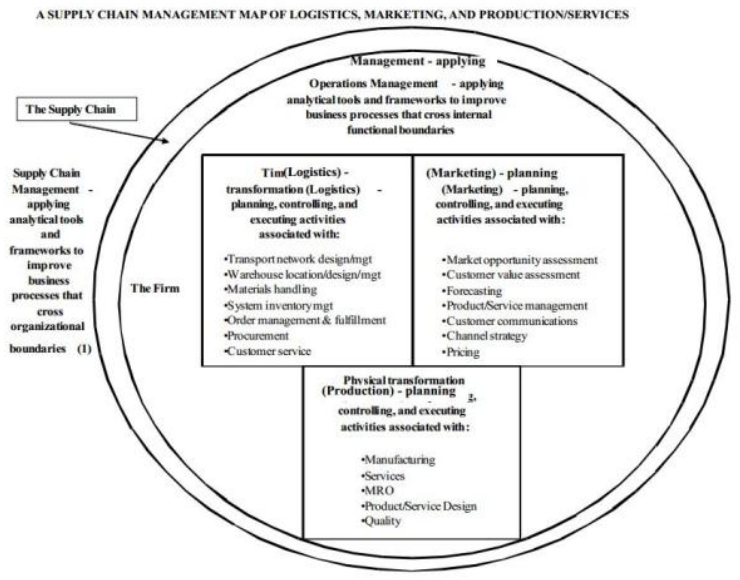

Figure 6. SCM, Logistic and Marketing Relation in Manufacturing (Adopted from [22])

\section{Subjects involved in the PBL MotoStudent}

When PBL is used, the influence of this methodology on the topics of the subjects is somewhat peculiar, as illustrated in Figure 7.

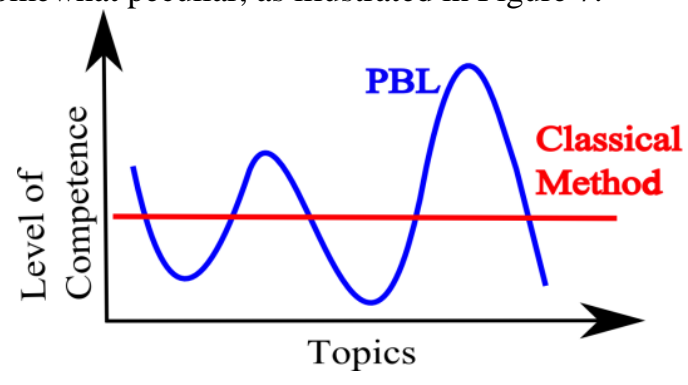

Figure 7. A comparison between the traditional method and PBL regarding the level of competence attained

In Figure 7, the different topics or subjects are represented on the $\mathrm{x}$ axis and in the $\mathrm{y}$ axis depicts the level of competence reached with each of the topics [34]. Traditional teaching tends to produce a similar level of competence in different topics, but PBL based teaching tends to produce different levels of 
competence for different subjects. In PBL, the level of competence will be higher in those topics that are more directly connected with the project, but in contrast to this, there may be topics that were not covered because they are not required for the project. This situation can occur during the application of PBL, and the main problem is the reduction in the level of competence that students can acquire in some subjects. This deficiency can be corrected from one year to another in order to prevent students from not acquiring the knowledge required in each of the subjects. The subjects that were included directly in this PBL were as follows (Figure 8):
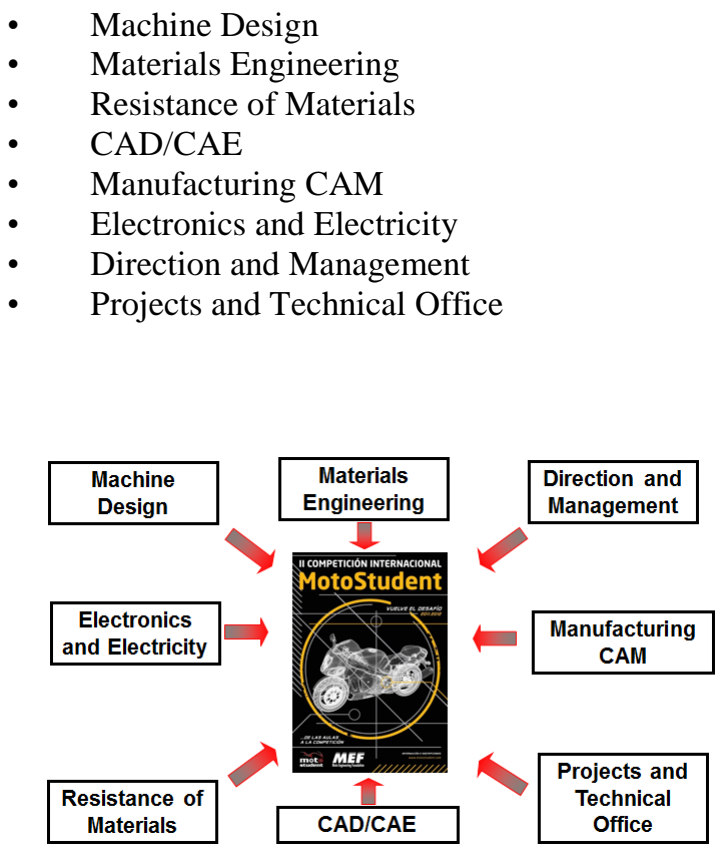

Figure 8. Subjects directly involved in this PBL (MotoStudent)

However, other subjects, especially of the first year engineering courses, were also indirectly involved in this PBL. Therefore, there was an assumption of a certain level of prior learning and competencies that students must acquire in their early semesters of an engineering degree. These subjects included Mathematics, Physics and drawing.

\section{Competencies acquired by students in the PBL MotoStudent}

Competence is understood as the ability to do or accomplish a task that the student can acquire during their education to be used in their professional future. Likewise, the professional capacity represents the ability to use good judgment and the knowledge, skills and attitudes associated with the profession for solving complex problems that can arise in the field of professional activity.
Basically, the competences related to technical training which are taught in engineering schools can be classified into:

1. Competencies Related to Knowledge

2. Competencies Related to Abilities and skills

3. Competencies Related to Attitudes and Values

\subsection{Competencies Related to Knowledge}

The competencies related to knowledge are of the type: General Competencies for learning, Academic Competencies related to subjects and Competencies Related to the professional world.

These competencies improve in the student different areas such as analysis, synthesis and conceptualization, and development and deepening of knowledge, skills and technical abilities. Professional competencies are closely related to research and innovation of technical solutions, with the transfer of knowledge and with general and specific procedures to practical situations.

\subsection{Competencies Related to Abilities and skills}

Competencies of the type abilities and skills are intellectual competencies, communication competencies, interpersonal competencies, and organization and management competencies.

These types of competencies are developed in students through systems thinking and critical thinking, information management and oral and written expression, Teamwork, and Respect for others and individual and group responsibility.

\subsection{Competencies Related to Attitudes and Values}

The competencies of the type attitudes and values are classified as professional development competencies and personal commitment. This type of competencies that are developed in students include initiative, perseverance and the systematization of the problems that the student can encounter in their professional life as well as personal and group responsibility.

\section{Teacher evaluation of PBL}

The evaluation of the PBL performed by the students must be focused on the project itself. The assessment should examine the knowledge accredited by each student individually regarding to the project and the academic content.

This assessment is performed as follows: 
In total, $60 \%$ of the final assessment is related to the project itself. From this $20 \%$ is given for the assessment of all equipment, and its assessment is based on delivering a project report and with the presentation of the project development to the teachers and classmates. This is delivered when a third of the project time committed has elapsed. This partial delivery serves in some way to keep track of the project, making it as realistic as possible and thus avoiding the project ending in failure. Teachers will in this way determine the expansion and improvement of the work done on the project, which will be graded once it has completed.

From the $60 \%$ assessment mark, $30 \%$ is awarded for the final evaluation of the project. The evaluation of the project is performed by a group exhibition when the project is fully completed. The remaining $10 \%$ of the assessment is the based on how the team has expanded the project since the interim report. This assessment and grading is made as follows:

- $0 \%$ if the expansion of the project is NOT well done.

- $5 \%$ if the expansion of the project is well done.

- $10 \%$ if all members of the group do well the requested expansion.

The remaining $40 \%$ is related to the student's individual subjective qualification, which allows assessing their participation, attitude and leadership within the group.

\section{Conclusions}

This paper has shown that in the Design, Development and Supply Management of a project; a case study of a motorcycle, students acquired a various set of skills that are vital for organization and industrial application as well as their professional life. Such projects allow participants to implement in a practical way much of the theoretical knowledge acquired in college, in real -life situations. As shown in the MotoStudent project students applied various calculations, design techniques, and innovations in order to solve or perform certain tasks. This case study illustrates that when students are properly coordinated they can perform challenging tasks such as assignment of appointments, planning as well as manufacturing. The most challenging part of the project is the implementation of some of the recent learning techniques referred as "Project-Based Learning". The paper shows the important roles that students should acquire in order to effective carry out a project.

Also, the knowledge acquired in each of the subjects offered during engineering schools with this new teaching technique is very similar to the knowledge acquired with traditional learning techniques as is shown by the marks obtained by the students. On the other hand, the motivation shown by students in following and implementation of the project is very important, mainly because it greatly reduces absenteeism classes compared to traditional techniques.

New product development has been transformed considerably over the last decade and management control systems have been key in contributing to this change. Currently, the effectiveness of product development organisations is classified not only by creativeness and autonomy, but also by controlling and exploiting their resources and capabilities, and the quality of their products [10]. Also, due to globalization of industry that has emerged in the late 20th century, new technologies have been applied by firms to enhance the process of new product development in order to maintain high competitive production with low cost and less time cycle to produce with high quality [30].

This paper also illustrated the significance of supply management as a part of operations management. The examples of applications of operations management and SCM in each of the three functions that have been shown in Figure 2 may prove beneficial in order to further distinguish between functional, operations, and supply chain management.

The outcomes point out that efficient knowledge management (KM) comprises the main dominant element that has a considerable control over project dynamics. In addition, a new product development (NPD) project is a competitive strategic tool for managers. Nevertheless, many NPDs projects are unsuccessful due to the dynamic character of essential success factors such as time, cost, quality, and scope. Thus, Scope and change management (CM) are critical factors that have a direct influence on the other three elements [28]. These results propose that managers need to pay more attention to both strategic orientation factors and structurerelated organizational competence factors to enhance product superiority. Additionally, it has been shown that there were some distinctions in factors that are related with high-quality productions between fundamental and incremental innovativeness [26].

This paper makes a contribution to the educational approaches of engineering and management students through the presentation of a project based learning approach that encompasses not just academic but also professional skills.

\section{References}

[1] American Marketing Association. (2007) Definition of marketing. Marketing Power.com

[2] Antoni, M. et al., (2005) "Inter-project improvement in product development", International 
Journal of Quality \& Reliability Management, 22(9), 876-893

[3] Blank, W. E. and Harwell, S. (1997) Promising Practices for Connecting High School to the Real World

[4] Branch, A. E. (2008) Global supply chain management and international logistics. Taylor \& Francis

[5] Cámara, C. P. and Eguizábal, A. J. (2008) "Quality of university programs for older people in Spain: Innovations, tendencies, and ethics in European higher education", Educational Gerontology, 34(4), 328-354

[6] Cooper, M. C. et al., (1997) "Supply chain management: more than a new name for logistics", The International Journal of Logistics Management, 8(1), pp. 1-14

[7] Council of Supply Chain Management Professionals (2007) www.cscmp.org, (Lombard, IL)

[8] Ewing, M.T. and Caruana, A. (1999) "An internal marketing approach to public sector management: The marketing and human resources interface." International Journal of Public Sector Management 12.1: $17-29$

[9] Galeana, L. (2009) Aprendizaje basado en proyectos

[10] Handfield, R.B. et al., (1999) "Involving suppliers in new product development?", California management review, 42, pp. 59-82

[11] Henard, D. H. and Szymanski, D. M. (2001) "Why some new products are more successful than others", Journal of marketing Research, 362-375

[12] Howe, V., Mathieu, R. G. and Parker, J. (2000) "Supporting new product development with the Internet", Industrial Management \& Data Systems, 100 (6), 277-284

[13] Mentzer, J. T. and Gundlach, G. (2010) "Exploring the relationship between marketing and supply chain management: introduction to the special issue". Journal of the Academy of Marketing Science, 38(1) pp. 1-4

[14] Keller, R. T. (2001) "Cross-functional project groups in research and new product development: Diversity, communications, job stress, and outcomes", Academy of management journal, 44(3), $547-555$
[15] Kessler, E. H. and Chakrabarti, A. K. (1998) "An empirical investigation into methods affecting the quality of new product innovations", International Journal of Quality Science, 3(4), 302319

[16] LaLonde, B. and Ginter, J. (2004) The Ohio State University 2002 survey of career patterns in logistics, Council of Supply Chain Management Professionals, available at: www.cscmp.org

[17] Leonard-Barton, D. (1992) "Core capabilities and core rigidities: A paradox in managing new product development", Strategic management journal, 13(S1), 111-125

[18] Maddi, M. S., Davis, P. and Geraghty, J. (2012) A Review of Strategic Procurement: Primary Step to Research on e-Procurement for engineering projects, 29th International Manufacturing Conference IMC, University of Ulster, Belfast, Northern Ireland

[19] Mangan J. and Christopher M. (2005) "Management development and the supply chain manager of the future." International Journal of Logistics Management, 16.2: 178-191

[20] Markham, T. (2003) Project based learning handbook: A guide to standards-focused project based learning for middle and high school teachers. Buck Institute for Education

[21] Maylor, H. and Gosling, R. (1998) "The reality of concurrent new product development", Integrated manufacturing systems, 9(2), 69-76

[22] Mentzer, J. T., Stank, T. P. and Esper, T. L. (2008) "Supply chain management and its relationship to logistics, marketing, production, and operations management." Journal of Business Logistics 29.1: 31-46

[23] Moursund, D., Bielefeldt, T. and Underwood, S. (2006) "Foundations for The Road Ahead: Projectbased learning and information technologies". Erişim tarihi, vol. 18

[24] Owens, J. D. (2007) "Why do some UK SMEs still find the implementation of a new product development process problematical?: An exploratory investigation", Management Decision, 45(2), 235251

[25] PMBOK Guide (2004), PMI

[26] Pugh, S. (1991) Total Design: Integrated Methods for Successful Product Engineering. Addison-Wesley Publishing Company, Harlow, UK 
[27] Richtnér, A. and Åhlström, P. (2010) “Top management control and knowledge creation in new product development", International Journal of Operations \& Production Management, 30 (10), 1006-1031

[28] Rodrigues, L. L., Dharmaraj, N. and Rao, B. S. (2006) "System dynamics approach for change management in new product development", Management Research News, 29(8), 512-523

[29] Statistical Office of the European Communities http://epp.eurostat.ec.europa.eu

[30] Davila, T. (2000) "An empirical study on the drivers of management control systems' design in new product development." Accounting organizations and society", 25 (4), pp. 383-409

[31] Teaching, C. E. and Environments, L. (2009) First results from TALIS

[32] Thomas, J.W. (2002) Project based learning overview. Novato, CA: Buck Institute for Education

[33] Trent, R. J. and Monczka, R. M. (1998) "Purchasing and supply management: trends and changes throughout the 1990s", Journal of Supply Chain Management 34 (4), pp. 2-11

[34] Valero, M. (2005) Las dificultades que tienes cuando haces PBL. La Educación Superior hacia la Convergencia Europea: Modelos basados en el aprendizaje (Cap. 8). MUZ

[35] Valle, A. (2012) Por qué están desmotivados los alumnos, VIII Jornadas de Convivencia Escolar. Ourense

\section{Acknowledgements}

The authors thank the Autonomous Government of La Rioja for its support through the 3rd Plan Riojano de I+D+I for project MODUVA. 